\title{
The Short-Term Effect of Eugenol on the Prevention of Experimentally Induced Myringosclerosis in a Rat Model
}

\author{
Original Investigation

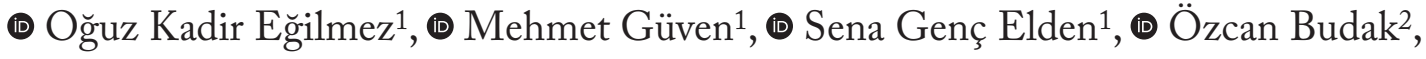 \\ ๑ Hüseyin Çakıroğlu ${ }^{3}$, $\odot$ Halil Elden ${ }^{1}$, $\odot$ Ebru Mihriban Güven ${ }^{4}$ \\ ${ }^{1}$ Department of Otorhinolaryngology, Sakarya University Training and Research Hospital, Sakarya, Turkey \\ ${ }^{2}$ Department of Histology and Embryology, Sakarya University Faculty of Medicine, Sakarya, Turkey \\ ${ }^{3}$ Sakarya University, Laboratory of Animal Experiments, Sakarya, Turkey \\ ${ }^{4}$ Health Sciences High School, Sakarya University, Sakarya, Turkey
}

\section{Abstract \\ This study was presented as an oral presentation at the Turkish National Otorhinolaryngology and Head and Neck Surgery Virtual Congress, $26^{\text {th }}-28^{\text {th }}$ of November, 2020. \\ ORCID ID of the authors: \\ O.K.E. 0000-0001-9623-9152 \\ M.G. 0000-0002-3665-2428; \\ S.G.E. 0000-0002-3479-1600 \\ Ö.B. 0000-0002-1285-0665; \\ H.Ç. 0000-0002-3445-6060; \\ H.E. 0000-0002-6306-4357; \\ E.M.G. 0000-0002-9743-2867. \\ Cite this article as: Eğilmez OK, Güven M, Genç Elden S, Budak Ö, Çakıroğlu H, Elden H, Güven EM. The Short-Term Effect of Eugenol on the Prevention of Experimentally Induced Myringosclerosis in a Rat Model. Turk Arch Otorhinolaryngol 2021; 59(2): 124-32.}

Corresponding Author: Oğuz Kadir Eğilmez; oguzegilmez@gmail.com

Received Date: 23.12.2020 Accepted Date: 27.02.2021

Content of this journal is licensed under a Creative Commons Attribution 4.0 International License. Available online at www.turkarchotolaryngol.net

\section{(c) (i) $\$$}

DOI: 10.4274/ta0.2021.6196

Objective: The aim of our study was to assess the possible short-term effects of topical and oral eugenol on the suppression of experimentally developed myringosclerosis (MS).

Methods: Four groups of seven male Wistar albino rats were used in the study. The tympanic membranes (TMs) of all subjects were myringotomized, and group 1 was given no treatment (as control group), group 2 received saline, group 3 had received topical eugenol and group 4 received oral eugenol.

Results: In macroscopic evaluation the control and saline groups showed much more MS compared to the topical and oral eugenol groups which had statistically significantly less changes $(\mathrm{p}<0.05)$. Fibrosis and inflammation regarding the lamina propria (LP) of the eardrums of the topical and oral eugenol groups were significantly less than those of the control and saline groups ( $\mathrm{p}<0.001)$. In microscopic evaluation, TMs were found to be thicker in the control and saline groups $(\mathrm{p}<0.001)$.

Conclusion: Our study showed that the application of topical and oral forms of eugenol reduced fibrosis and prevented the advancement of MS in the LP of the TMs in the short-term. More studies with different extracts are needed to investigate the efficacy of phytotherapeutic agents for preventing MS development following myringotomy.

Keywords: Tympanic membrane, myringosclerosis, antioxidants, eugenol, rats, animal experimentation

\section{Introduction}

Myringosclerosis (MS) is the end-stage of the chronic inflammation, infection or injury in the tympanic membrane (TM) and usually seen following interventions such as ventilation tube insertion. It is represented by the hyaline degeneration of the elastic fibrils and calcification in the lamina propria (LP) of the TM $(1,2)$. 
In pediatric patients, otitis media with effusion (OME) is a common disorder which often requires a procedure like myringotomy or ventilation tube placement on the TM between the external ear canal and middle ear (2). There is an increased possibility of MS in patients who had ventilation tubes placed $(3,4)$. Several studies reported that the incidence of MS was much higher in cases with a history of ventilation tube placement compared to without. These studies also reported the incidence in pediatric patients to range between 28 and $61 \%(5,6)$.

Although the exact etiopathology of MS is unknown, hyperoxic conditions and increased oxygen-derived free radicals caused by trauma have been attributed to play an important role $(7,8)$. Setting out from this point of view, various anti-inflammatory and antioxidant agents have been used in experimental studies to reduce and prevent the effects of these free radicals $(9,10)$.

Eugenol $\left(\mathrm{C}_{10} \mathrm{H}_{12} \mathrm{O}_{2}\right.$ or $\left.\mathrm{CH}_{3} \mathrm{C}_{6} \mathrm{H}_{3}\right)$ is a yellowish volatile essential oil secured from Eugenia caryophyllata leaves and buds which is primarily endemic in India, Madagascar, and Indonesia (11). Its anti-mutagenic, anti-inflammatory, analgesic, antimicrobial, and anti-carcinogenic effects have been shown in previous studies (12). The antioxidant efficiency of eugenol commixtures, which comes from their methoxy-phenolic formation, has also been reported in several experimental models (12). Eugenol is considered non-toxic, and safe by the U.S. Food and Drug Administration (13).

In our study, the purpose was to explore the possible effects of eugenol as an anti-inflammatory and antioxidant molecule on MS development in an experimental Wistar Albino rat model using otomicroscopic and histopathological methods.

\section{Methods}

\section{Maintenance of Experimental Material}

All methods used in this experiment met the ethical standards of the institution Sakarya University Animal Experiments Local Ethics Committee, (no: 04/03/2019-11) and complied with the ARRIVE protocol for animal experiments and were carried out according to the National Institutes of Health Protocol for the Use and Care of Laboratory Test Subjects (NIH Publications no: 8023, revised in 1978). Twenty-eight healthy male Wistar albino rats with a weight of 300-350 g were used in the experiment. All procedures were completed and all test subjects were cared for by the authors. Test subjects were kept in temperature-measured $\left(23 \pm 2{ }^{\circ} \mathrm{C}\right)$ and humidity-measured $(50 \pm 10 \%)$ chambers with factitious lighting from 8:00 a.m. to 8 p.m. and with free access to food and water They were given classic commercial rat food and fountain water and handled after seven days of segregation and acclimatization.

\section{Experimental Design and Surgical Procedure}

Intramuscular application of a combination of ketamine hydrochloride $(50 \mathrm{mg} / \mathrm{kg})$ (Ketalar ${ }^{\circledR}$ Eczacıbaşı ParkeDavis, İstanbul, Turkey) and xylazine hydrochloride (5 $\mathrm{mg} / \mathrm{kg}$ ) (Alfazyne ${ }^{\circledR}$ Alfasan International B.V., Woerden, Netherlands) was used to anesthetize the subjects. A warming blanket was used to maintain body temperature at $35{ }^{\circ} \mathrm{C}$, and rectal temperature was continuously monitored during anesthesia. Otoscopic examinations were done to observe the ear canal and the TM. In the animal selection phase, rats with otitis media and/or externa, and rats with perforation and sclerosis in the eardrums were removed from the study. A perforation with a sterile pick was done in the posterior superior one-fourth of the TMs in both ears under the otomicroscope by the same author. Intratympanic bleeding was not observed during this procedure. Then all subjects were randomly partitioned into four groups of seven rats each.

Group 1: Control group, received no treatment, only myringotomy was performed.

Group 2: Subjects in this group received saline solution topically three times, immediately after myringotomy, at the $24^{\text {th }}\left(\right.$ day $\left.1^{\text {st }}\right)$ and $48^{\text {th }}$ hours (day $2^{\text {nd }}$ ). A syringe was used to drop $0.1 \mathrm{~mL}$ saline solution into the outer ear canal.

Group 3: Immediately after myringotomy, subjects in this group were treated using a gelfoam fragment soaked in 0.1 $\mathrm{mL}$ eugenol (Eugenol ReagentPlus ${ }^{\circledR}$, 99\%; Sigma-Aldrich Chemical Co., Merck, Darmstadt, Germany). The solution was applied on the perforation of both TMs in each rat, at the $24^{\text {th }}$ and $48^{\text {th }}$ hours, and $0.1 \mathrm{~mL}$ eugenol was dropped into the ear canal with the help of a syringe with the second and third doses.

Group 4: This group received $50 \mathrm{mg} / \mathrm{kg}$ eugenol orally five times using the gavage method; immediately after myringotomy, at the $24^{\text {th }}$ hour (day $\left.1^{\text {st }}\right), 48^{\text {th }}$ hour (day $2^{\text {nd }}$ ), $72^{\text {nd }}$ hour (day $3^{\text {rd }}$ ) and $120^{\text {th }}$ hour (day $\left.5^{\text {th }}\right)$.

The oral doses of eugenol were specified based on the principles of previous experimental concepts (12).

\section{Otomicroscopic Examination}

On the $15^{\text {th }}$ and final day of the experiment otomicroscopic examination was performed after all test subjects were euthanized and decapitated. The author evaluating and scoring the inflammation stage of the TMs was blinded to the animal groups. The rate of MS in the pars tensa of the eardrums was assessed semi-quantitatively and graded by the scoring system indicated by Mattsson et al. (14), as normal, mild, moderate, and severe. Normal: no distinguishable MS; Mild: white halo around umbo; Moderate: white halo around umbo and a white strip beside the handle of the malleus and 
along the annulus; and Severe: converging whitish deposit forming a horseshoe pattern.

\section{Temporal Bone Dissection and Histopathological Evaluation}

Following otomicroscopic examination, temporal bone dissection was performed to access the tympanic bulla and the TM. A horizontal incision was made in the occipital area and the skin was lifted forward. The temporalis muscle and the periosteum were raised over the parietal bone, and then over the squamous part of the temporal bone. While retracting the auricle laterally, the cartilaginous outer ear canal was disconnected from the tympanic ring with a blunt dissection. The mastoid bulla was revealed when the elevation of the muscles in the subperiosteal plane was performed. At the next step, the squamous part was sectioned from the frontal, parietal, ethmoid, and palatine bones; the mastoid fragment was sectioned from the occipital bone; the petrous part was sectioned from the sphenoid bone; and the bulla was sectioned from the sphenoid and occipital bones. Finally, the temporal bone was sectioned from the surrounding muscle tissues and separated from the skull.

The temporal bones were fixed in $10 \%$ formaldehyde quick fix for 24 hours and then decalcified with formic acid for ten days. After the decalcification process, copies were separated into two fragments through a line that divided the perforation vertically up to the handle of the malleus. All slices were enclosed in paraffin, sectioned in $5 \mu \mathrm{m}$ thickness, and stained with Masson's Trichrome and Hematoxylin \& Eosin (H\&E) staining techniques to assess fibrosis, inflammation, and thickness in the TMs of every subject. To examine the sclerotic changes and collagen fibrils in the connective tissue of the LP, Masson's Trichrome staining was performed. In H\&E staining, calcification appeared as dark purplish pink color with irregularly bordered areas. With Masson's Trichrome technique, sclerotic areas emerged as blue spaces rather than white. The healed perforation areas where the most inflammation occurred were evaluated to measure the thickness of the TMs.

All samples were analyzed by a pathologist blinded to the groups. Micro calculations were done quantitatively on a high-resolution light microscope (Eclipse E200 Invert; Nikon, Tokyo, Japan) under 40x to $100 x$ magnification. Severity of fibroblastic proliferation in the LPs and the degree of sclerotic lesions in the TMs were graded as follows: "0" if no distinguishable MS; "1" if mild; "2" if moderate; and " 3 " if severe. And the intensity of the inflammation was graded as: " 0 " if there was no inflammation; "1" if mild; " 2 " if moderate; and " 3 " if there marked inflammation and intense exudation and granulation.

\section{Statistical Analysis}

All data were analyzed with SPSS for Windows v22.0 (SPSS; IBM Co., Armonk, NY, USA). Descriptive statistics was used to determine mean, median (minimum-maximum), standard deviation, frequency distribution and percentage of individual and aggregate data. The Kolmogorov-Smirnov test was used to verify the normality of data distribution. In each group, mean thickness of the TMs was compared with one-way ANOVA and post hoc tests and otomicroscopic, inflammation and MS scores were compared with student's t-test. Categorical variables were evaluated with the chisquare test. A p-value $<0.05$ was considered statistically significant.

\section{Results}

\section{Otomicroscopic Examination}

On the final day of the experiment, it was observed that all TM perforations had improved and closed. More MS plaques were noticed in groups 1 and 2, whereas the TMs in group 3 (topical eugenol) and group 4 (oral eugenol) revealed significantly less or no sclerotic plaque (Figures 1a-d).

Figure 2 shows the calculations of MS degrees as assessed by otomicroscopy. MS degree was "moderate" or "severe" in $92.9 \%$ of the TMs in group 1 (control) and in $78.6 \%$ in group

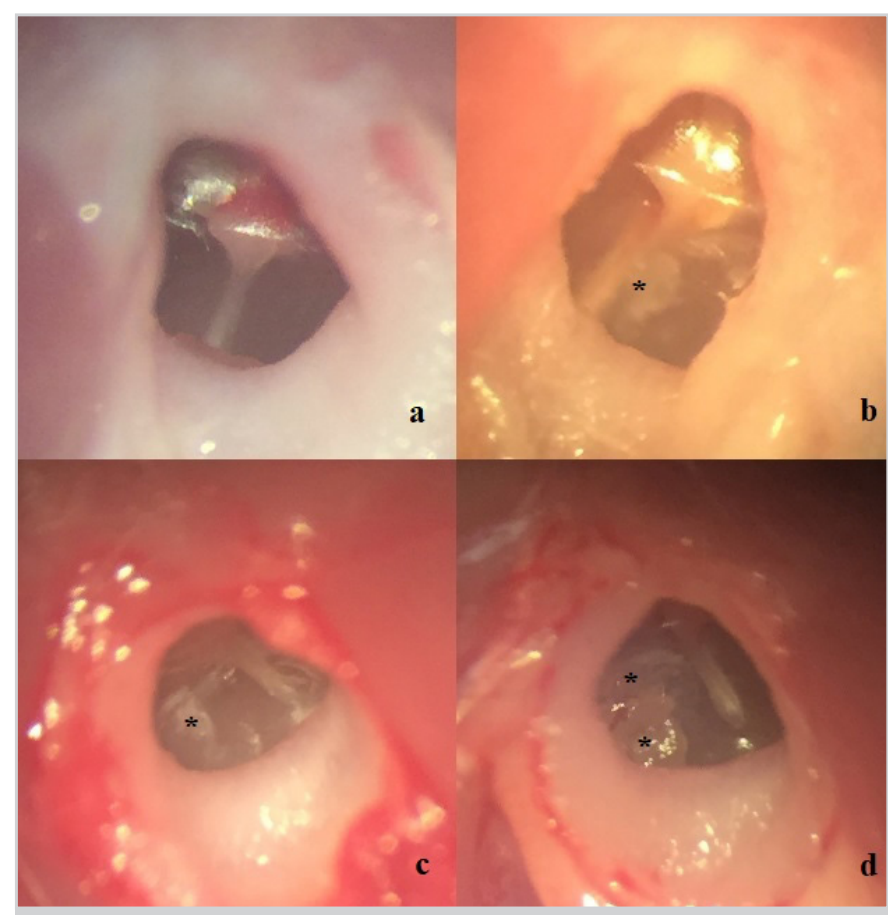

Figure 1.a-d. Otomicroscopic views of the TMs laterally on the final day of the experiment. a. Otomicroscopic view of TM from group 3 (topical eugenol), MS degree was normal. b. Otomicroscopic view from group 4 (oral eugenol), MS degree mild. Asterisk shows the white sclerotic plaques near the umbo and the healed myringotomy site. c. Otomicroscopic view from group 2 (topical saline solution), MS degree moderate. Asterisk shows the sclerotic plaques around the umbo, and adjacent to the handle of the malleus. d. Otomicroscopic view of TM from group 1 (no treatment-control group), MS degree severe. Asterisks show the dense sclerotic areas TM: Tympanic membrane, MS: Myringosclerosis 
2 (saline) but "none" or "mild" in $100 \%$ of TMs in groups 3 and 4 . Sclerotic plaques were less in group 3 than in group 4 ("none" degree was $64.3 \%$ in group 3, 35.7\% in group 4). The conclusions in the short-term were significantly more pronounced in groups 1 and $2(\mathrm{p}<0.001)$. There were no significant differences between groups 1 and 2 and groups 3 and 4 ( $\mathrm{p}=1, \mathrm{p}=0.141$, respectively).

\section{Histopathological Examination}

In group 1, $12(85.7 \%) \mathrm{TMs}$ had moderate or marked (degrees "2" and " 3 ") and two TMs (14.3\%) had none or mild (degrees "0" and "1") inflammation. In group 2, 13 (92.9\%) TMs had moderate or marked and one (7.1\%) had none or mild inflammation. But in the topically treated group (group 3), 14 (100\%) TMs had none or mild (2 TMs were "0" and 12 TMs were " 1 ") and $0(0 \%)$ had moderate or marked inflammation, and in group 4, 10 (71.4\%) TMs had none or mild and $4(28.6 \%)$ TMs had moderate or marked inflammation (Figures 3a-d). To summarize, inflammation in LP were significantly more severe in groups 1 and 2 compared to groups 3 and 4 in this short period (Figure 4) $(\mathrm{p}<0.001)$.

The extension of the fibroblastic proliferation and sclerosis in the short-term were less in the TMs of groups 3 and 4. Thirteen TMs (92.9\%) in group 1 and all TMs (100\%) in group 2 had degree " 2 " or degree " 3 " fibrosis. Conversely, in group 3, 12 TMs (85.7\%) and in group 4, 11 TMs (88.6\%) had degree "0" or degree "1" fibroblastic proliferation. There were significant differences among the groups in terms of fibroblastic proliferation and sclerotic plaques $(\mathrm{p}<0.001)$ (Figures 5 and $6 \mathrm{a}-\mathrm{d}$ ).

In the short study period, the thickness of perforated regions in groups 1 (control) and 2 (saline) were measured thicker than those of groups 3 (topical eugenol) and 4 (oral eugenol). The thinnest TMs were in group 3. Mean thickness of the

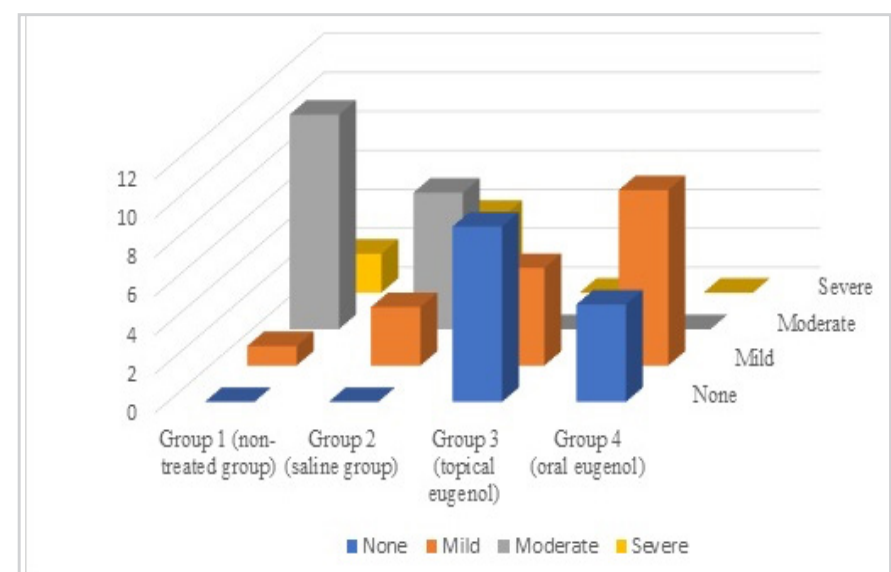

Figure 2. Graphical analysis of otomicroscopic grading of MS in tympanic membranes

MS: Myringosclerosis
TMs was $112.6 \pm 19.46 \mu \mathrm{m}$ in Group “; $97.93 \pm 7.64 \mu \mathrm{m}$ in group 2; $62.8 \pm 10.92 \mu \mathrm{m}$ in group 3 , and $80.36 \pm 7.66 \mu \mathrm{m}$ in group 4 (Figure 7). In terms of the thickness of TMs, statistically significant differences were separately observed between groups 1 and $3(p<0.001)$, groups 1 and $4(p<0.001)$, groups 2 and $3(p<0.001)$, groups 2 and $4(p<0.001)$ and groups 3 and $4 \quad(p<0.001)$. There were no statistically significant differences between groups 1 and 2 in terms of mean thickness of TM $(p=0.075)$.

\section{Discussion}

MS is defined as the reaction of tympanosclerosis localized to the TM. It is a frequent condition in OME, recurrent otitis media, chronic otitis media, and surgical interventions such as myringotomy and VT insertion (15, 16). Whilst there is no exact information on its etiology and pathogenesis, recent studies have emphasized that mechanical injury, intratympanic hemorrhage, foreign body reaction to VT, hyperoxygenation and oxygen-derived free radicals, and autoimmunity might be the key points in the occurrence of MS $(15,16)$. Mattsson et al. (14) indicated that after myringotomy procedure, the sclerotic changes

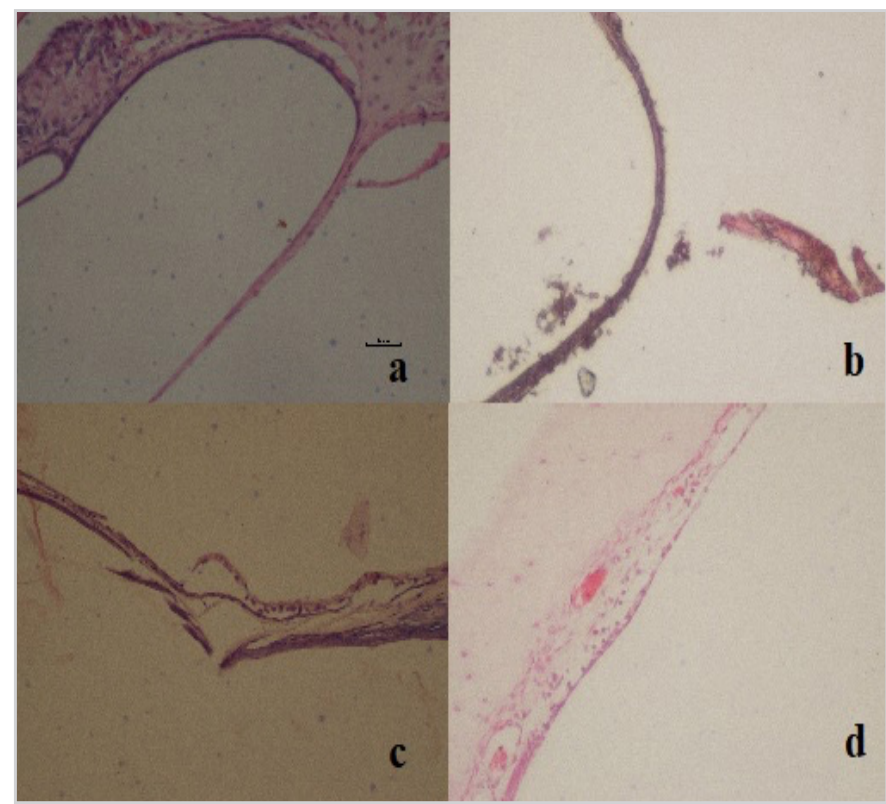

Figure 3. a-d. Light microscopic views of TM of rats (hematoxylin and eosin staining, all four photographs are at original magnification 200x). a. Photograph of pars tensa of a rat from group 3 (topical eugenol). There is no evidence of inflammation in LP of TM (Inflammation degree 0). b. Photograph of pars tensa of a rat from group 4 (oral eugenol). There is mild inflammation in the LP (Inflammation degree 1).c.Photograph of TM from group 2 (topical saline solution). Inflammation is more apparent, and the TM is comparatively thicker (Inflammation degree 2). d. Photograph of a rat from group 1 (no treatment-control group) showing extensive inflammation in the LP and thicker TM compared to other groups (Inflammation degree 3)

TM: Tympanic membrane, MS: Myringosclerosis, LP: Lamina propria 
in pars flaccida of the TM evolved within nine hours and inflammatory response after 12-24 hours.

Whereas MS is identified histologically in $80 \%$ of cases after myringotomy it can be identified under otomicroscopy in only $40 \%$ of the cases. This suggests that the actual number of tympanosclerosis cases detected with otomicroscopy could be two-fold (6). To support this, in a study by Santos et al. (17), the sensitivity and specificity of otomicroscopy was found $80 \%$ and $75 \%$, respectively. The authors concluded that histolopathological evaluation was a better method than otomicroscopy for diagnosing MS. Thickness, inflammation, and fibrosis can also be evaluated by the histopathological methods. Based on the results of our study, we also believe that the histological method is stronger than otomicroscopy for determining MS.

In the light of the literature, we preferred the myringotomy model to set up MS in our study. We sacrificed the subjects on the $15^{\text {th }}$ day in order to see the potential defensive effects of the topical and oral eugenol on the evolution of MS with otomicroscopic and histopathological findings, considering

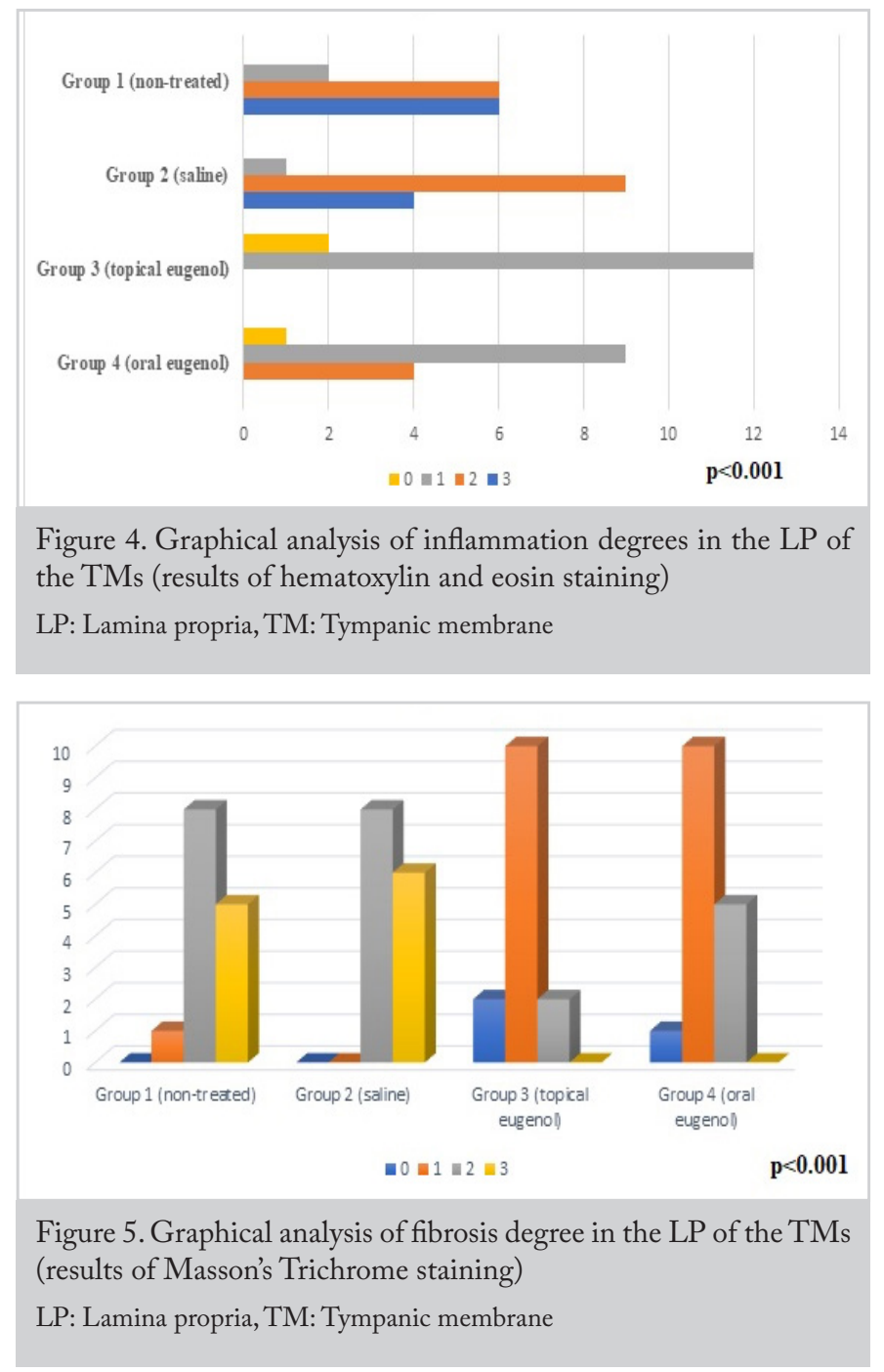

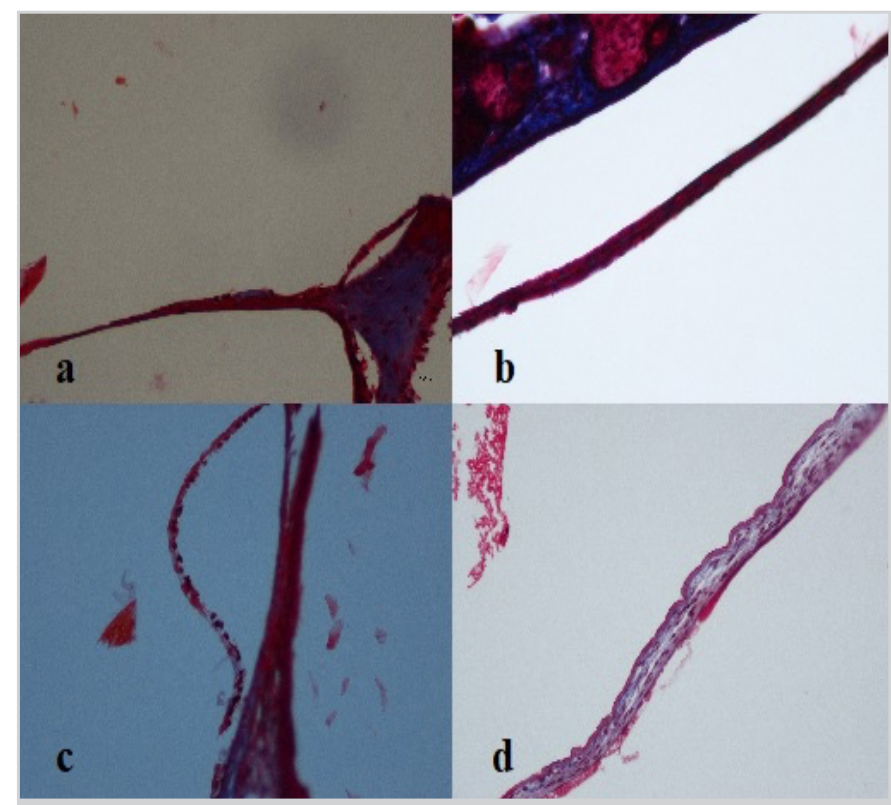

Figure 6. a-d. Light microscopic views of TM of rats (Masson's Trichrome staining, all four photographs are at original magnification 200x). a. Photograph of pars tensa of a rat from group 3 (topical eugenol). There is no evidence of sclerosis in LP of TM (fibrosis degree 0). b. Photograph of pars tensa of a rat from group 4 (oral eugenol). There is mild fibroblastic activity in the LP (fibrosis degree 1). c. Photograph of a TM from group 2 (topical saline group). Sclerosis degree is more apparent, and the TM is comparatively thicker (fibrosis degree 2). d. Photograph of a rat from group 1 (no treatment-control group) showing increased fibroblastic activity in the LP and thicker TM compared to other groups (fibrosis degree 3 )

TM: Tympanic membrane, LP: Lamina propria

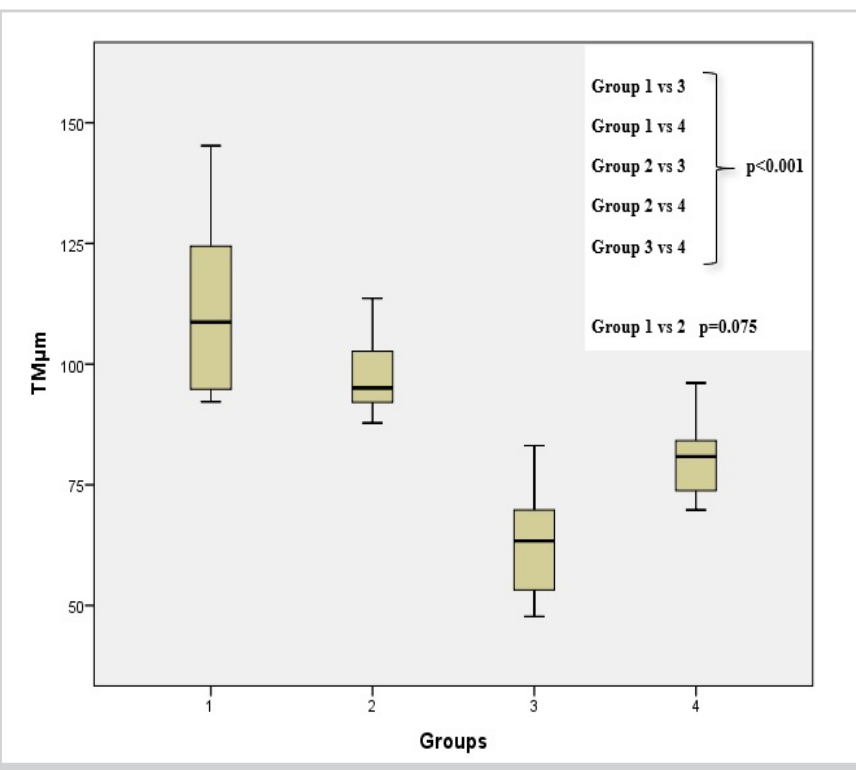

Figure 7. Mean, standard deviation, and statistical analysis of thickness of the TMs in $\mu \mathrm{m}$ (micrometer)

TM: Tympanic membrane 
that it may have a preventive outcome in the first phase of MS development explained in the pathogenesis in the shortterm period while experimental MS was forming.

Studies on this topic have focused on reducing or preventing MS by application of free radical scavengers, anti-inflammatory, and antioxidants agents. L-carnitine, selenium, Ginkgo biloba, ascorbic acid, N-acetylcysteine, zinc aspartate, vitamin $\mathrm{C}$ and $\mathrm{E}, \mathrm{N}$-nitro $\mathrm{L}$ - arginine methyl ester (L-NAME), Caffeic acid phenyl ester (CAPE), Hypericum perforatum, rosmarinic acid, montelukast, melatonin, dexamethasone and enoxaparin sodium have been used for this purpose in the current literature $(1,2,6,9,15,18-29)$. The effect of free radical scavengers is to arrest the formation of free radicals and active oxygen species, scavenging them, and repairing the damage. The aforementioned antioxidants, enzymes, and extracts were administered to the TMs of the myringotomized subjects, and the results indicated that the development of MS is inhibited or weakened with the therapy with antioxidants and free radical scavengers.

The antimicrobial, antimutagenic, analgesic, anticarcinogenic, anti-inflammatory, and antioxidant effects of eugenol, a yellowish fatty liquid obtained from the clove plant, are reported in the literature. It grows in the different parts of the world, especially in Indonesia, India and Madagascar (11). Some examples to the studies that have explored their effects are: a study by Islam et al. (30) reporting that eugenol strengthens the anticarcinogenic characteristic of cisplatin by limiting the Nuclear Factor kappa-B (NFkB) pathway when used together. The effect of eugenol counter to cisplatin-caused nephrotoxicity was studied by Rao et al. (31) and it was determined that eugenol protected against cytotoxic effects of cisplatin through free radical scavenging activities. Therapeutic action of eugenol against arseniccaused cardiotoxicity was also investigated. Binu et al. (32) reported that in heart tissue, arsenic, by its cytotoxic effect, increased the levels of malondialdehyde (MDA)-a marker of lipid peroxidation; diminished grades of glutathione (GSH)one of the important non-enzymatic endogenous antioxidant molecules. Also, they reported that when eugenol given orally at $5 \mathrm{mg} / \mathrm{kg}$, antioxidant levels in tissues increased, membrane peroxidation was regulated, and thereby, heart rate was normalized. Additionally, MDA levels decreased, and GSH and Glutathione Peroxidase (GPx) levels increased as a conclusion of eugenol treatment. Consequently, they suggested that eugenol showed cytoprotective properties by preventing lipid peroxidation and by protecting nonenzymatic and enzymatic antioxidant pathways (32). Said and Rabo (33) in their experimental study, investigated the preventive effect of eugenol in aluminum-caused brain damage, and reported eugenol as a likely neuro-protective factor because of its anti-apoptotic and antioxidant characteristics. Martínez-Herrera et al. (34) used eugenol for gingival inflammation and reported that eugenol showed an anti-inflammatory effect even at low doses. Regarding the effects of eugenol on the ear, we can see that there are not many studies on this subject in the current literature. A study by Yadav et al. (35) in which the antibacterial activity of eugenol is mentioned reported that eugenol at sub-MIC (minimum inhibitory concentration) significantly decreased $88 \%$ S. aureus colonization in rat middle ear. A study about cisplatin-induced ototoxicity by Sakat et al. (12) on increased MDA levels and decreased GPx and superoxide dismutase (SOD) activities, reported that eugenol reduced these effects in the cochlea and prevented oxidative stress in the inner ear and exhibited otoprotective activity.

Eugenol has been approved by the US Food and Drug Administration to be used as an additive in the food industry, a natural antiseptic and analgesic in dentistry, and as scent in the cosmetics industry (11). Although it has been reported as safe, there are some publications in the literature regarding its toxic effect. In a case study, a twoyear-old child who consumed $5-10 \mathrm{~mL}$ of clove oil was reported to develop impaired liver function and experience disseminated intravascular coagulopathy. Results showed similarities between paracetamol- and eugenol-poisoning in terms of hepatotoxicity (36). In an experimental study, intravenously infused $4 \mu \mathrm{L}$ and $8 \mu \mathrm{L}$ eugenol was reported to have caused hemorrhagic pulmonary edema and acute respiratory distress, and some of the damage was suggested to be prone oxidative stress (37). In an in vitro study, eugenol was administered to isolated rat hepatocytes for five hours, and toxic effects and cell damage were seen in more than $85 \%$ of the cells. Applying acetylcysteine to the same cell line showed prevention on cell death (38). Anesthetic doses of eugenol were studied on African clawed frogs by Goulet et al. (39) and injury in kidney and cell apoptosis and some morphological modification in renal cells were demonstrated. In another study, eugenol was given orally to the rats in different doses over a 15-day period, and some changes in blood chemistry, such as rise in total bilirubin levels, alanine aminotransferase, and aspartate aminotransferase were observed (40). In the literature, there is controversy about the potency of eugenol in inducing hypersensitivity and allergy. Several adverse effects have been reported after using dental products containing eugenol. Localized irritation of the skin, ulcers, tissue necrosis, allergic dermatitis, and even anaphylactic shock were also observed (41). Some studies, on the other hand, showed that clove oil or eugenol alone had low activity in stimulating these kinds of allergic effects $(42,43)$.

A limitation of our study may be that the absence of an audiological examination on the subjects. Because our focus was on the wound healing and anti-inflammatory effects of eugenol, otoacoustic emissions (OAE) and/or auditory brainstem response $(\mathrm{ABR})$ were not considered in ototoxicity 
evaluation. Further studies are needed to evaluate whether the eugenol has positive or negative effects on hearing.

\section{Conclusion}

There are many studies that have investigated the antioxidant and anti-inflammatory effects of eugenol, but to the best of our knowledge, this is the first study in the literature that has evaluated eugenol in preventing MS advancement (11). When the short-term otomicroscopic and histopathologic outcomes of the experimental study were examined, it was found that development of MS and thickness of TMs after myringotomy were significantly decreased in the topical and oral eugenol treatment groups, compared to the control and saline groups. In conclusion, both the topical and the oral administration of eugenol lowered fibrosis and restricted the advancement of MS. More studies with different extracts are needed to investigate the efficacy of phytotherapeutic agents in order to prevent MS developing after myringotomy.

Ethics Committee Approval: All methods used in this experiment met the ethical standards of the institution Sakarya University Animal Experiments Local Ethics Committee, (no: 04/03/2019-11).

Informed Consent: Animal experiment study.

Peer-review: Externally peer-reviewed.

\section{Authorship Contributions}

Conception: O.K.E., H.E., Design: O.K.E., Supervision: M.G., Materials: O.K.E., S.G.E., Ö.B., H.Ç., H.E., Data Collection and/or Processing: O.K.E., S.G.E., H.E., E.M.G., Analysis and/or Interpretation: Ö.B., H.Ç., Literature Review: O.K.E., S.G.E., Ö.B., H.Ç., H.E., E.M.G., Writing: O.K.E., M.G., S.G.E., Ö.B., H.Ç., H.E., E.M.G., Critical Review: M.G., E.M.G.

Conflict of Interest: No potential conflict of interest relevant to this article was reported.

Financial Disclosure: The authors declared that this study has received no financial support.

\section{Main Points}

- Myringosclerosis is the end-stage of the chronic inflammation, infection or injury in the tympanic membrane.

- Possible preventive effects of the topical and oral forms of eugenol on myringosclerosis development were investigated in this experimental study.

- Otomicroscopic examination and histopathologic methods were used to evaluate the degrees of inflammation and fibrosis in tympanic membranes.

- It was demonstrated that the topical and oral utilization of eugenol lowered inflammation and fibrosis and restricted the development of MS.

\section{References}

1. Kargin Kaytez S, Kavuzlu A, Yumusak N, Oçal R, Akkoca O. Is there any effect of montelukast on prevention of myringosclerosis after myringotomy in a rat model? Eur Arch Otorhinolaryngol 2019; 276: 57-62. [Crossref]

2. Eğilmez OK, Kökten N, Ekici AI, Kalcıŏlu MT, Yesilada E, Tekin M. The effect of Hypericum perforatum L. (St. John's Wort) on prevention of myringosclerosis after myringotomy in a rat model. Int J Pediatr Otorhinolaryngol 2015; 79: 1128-34. [Crossref]

3. Zielnik-Jurkiewicz B, Olszewska-Sosińska O, Rakowska M. [Results of treatment with tympanostomy tubes in children with otitis media with effusion] (Article in Polish). Otolaryngol Pol 2006; 60: 181-5. [Crossref]

4. Slack RW, Maw AR, Capper JW, Kelly S. Prospective study of tympanosclerosis developing after grommet insertion. J Laryngol Otol 1984; 98: 771-4. [Crossref]

5. Asiri S, Hasham A, al Anazy F, Zakzouk S, Banjar A. Tympanosclerosis: review of literature and incidence among patients with middle-ear infection. J Laryngol Otol 1999; 113: 1076-80. [Crossref]

6. Üstündağ M, Koçyiğit M, Bulut E, Altaner Ş, Taş A, Yağız R. Effect of topical dexamethasone for preventing experimentally induced myringosclerosis. Turk Arch Otorhinolaryngol 2017; 55: 3-9. [Crossref]

7. Song JJ, Kwon SK, Cho CG, Park SW. The effect of caffeic acid phenethyl ester on the prevention of experimentally induced myringosclerosis. Int J Pediatr Otorhinolaryngol 2007; 71: 128791. [Crossref]

8. Dogan E, Erdag TK, Sarioglu S, Ecevit MC, Ikiz AO, Güneri EA. The preventive effect of $\mathrm{N}$-nitro L-arginine methyl ester in experimentally induced myringosclerosis. Int $\mathrm{J}$ Pediatr Otorhinolaryngol 2011; 75: 1035-9. [Crossref]

9. Özdemir D, Ağrı İ, Bakirtaş M, Ağrı A, Mehel DM, Çelebi M, et al. The effect of rosmarinic acid on the prevention of myringosclerosis. Int J Pediatr Otorhinolaryngol 2019; 126: 109597. [Crossref]

10. Kokten N, Egilmez OK, Dogan Ekici AI, Kalcioglu MT, Tekin M, Yesilada E. The effect of Nigella sativa oil on prevention of myringosclerosis in a Guinea pig model. Int J Pediatr Otorhinolaryngol 2016; 88: 52-7. [Crossref]

11. Nejad SM, Özgüneş H, Başaran N. Pharmacological and toxicological properties of eugenol. Turk J Pharm Sci 2017; 14: 201-6. [Crossref]

12. Sakat MS, Kilic K, Akdemir FNE, Yildirim S, Eser G, Kiziltunc A. The effectiveness of eugenol against cisplatin-induced ototoxicity. Braz J Otorhinolaryngol 2019; 85: 766-73. [Crossref]

13. National Toxicology Program. Carcinogenesis studies of eugenol (CAS No. 97-53-0) in F344/N rats and B6C3F1 mice (feed studies). Natl Toxicol Program Tech Rep Ser 1983; 223: 1-159. [Crossref] 
14. Mattsson C, Stierna P,Hellström S. Treatment with dexamethasone arrests the development of myringosclerosis after myringotomy. Am J Otol 2000; 21: 804-8. [Crossref]

15. Ozcan C, Görür K, Cinel L, Talas DU, Unal M, Cinel I. The inhibitory effect of topical $\mathrm{N}$-acetylcysteine application on myringosclerosis in perforated rat tympanic membrane. Int J Ped Otorhinolaryngol 2002; 63: 179-84. [Crossref]

16. Barfoed C, Rosborg J. Secretory otitis media. Long-term observations after treatment with grommets. Arch Otolaryngol 1980; 106: 553-6. [Crossref]

17. Santos PF, Leal MC, Peixoto C, Caldas Neto S, Rosas ST. Otomicroscopic and histologic findings of induced myringosclerosis in rats: a critical study of an experimental model. Braz J Otorhinolaryngol 2005; 71: 668-74. [Crossref]

18. Ayata M, Kaptan Z, Uzunkulaoğlu H, Akyıldız İ, Tüzüner A, Ünverdi H, et al. Effect of enoxaparin sodium on experimentallyinduced myringosclerosis in rats. J Int Adv Otol 2015; 11: 192-5. [Crossref]

19. Güneş A, Mutlu M, Akın İ, Köybaşioğlu F, Güvey A, Karasu $\mathrm{MF}$, et al. The impact of systemic and local administration of ascorbic acid on traumatic perforation of tympanic membrane and myringosclerosis. J Int Adv Otol 2015; 11: 48-52. [Crossref]

20. Vuralkan E, Tokgöz SA, Simsek G, Koybasioglu F, Han U, Caliskan $\mathrm{M}$, et al. Effect of local use of L-carnitine after myringotomy on myringosclerosis development in rats. J Laryngol Otol 2013; 127 : 468-72. [Crossref]

21. Yildirim I, Ciralik H, Okur E, Aydoğan B, Kiliç MA. The effect of intraperitoneal administration of zinc aspartate on myringosclerosis in perforated tympanic membranes of rats. Kulak Burun Bogaz Ihtis Derg 2009; 19: 263-7. [Crossref]

22. Akbaş Y, Pata YS, Görür K, Polat G, Polat A, Ozcan C, et al. The effect of L-carnitine on the prevention of experimentally induced myringosclerosis in rats. Hear Res 2003; 184: 107-12. [Crossref]

23. Kazıkdaş KC, Güneli E, Tuğyan K, Erbil G, Küme T, Uysal $\mathrm{N}$, et al. The effect of melatonin on experimentally-induced myringosclerosis in rats. Kulak Burun Bogaz Ihtis Derg 2010; 20: 299-304. [Crossref]

24. Emir H, Kaptan ZK, Samim E, Sungu N, Ceylan K, Ustun H. The preventive effect of ginkgo biloba extract in myringosclerosis: study in rats. Otolaryngol Head Neck Surg 2009; 140: 171-6. [Crossref]

25. Spratley JE, Hellström SO, Mattsson CK, Pais-Clemente M. Topical ascorbic acid reduces myringosclerosis in perforated tympanic membranes. A study in the rat. Ann Otol Rhinol Laryngol 2001; 110: 585-91. [Crossref]

26. Mattsson C, Magnuson K, Hellström S. Myringosclerosis caused by increased oxygen concentration in traumatized tympanic membranes. Experimental study. Ann Otol Rhinol Laryngol 1995; 104: 625-32. [Crossref]
27. Görür K, Ozcan C, Polat A, Unal M, Tamer L, Cinel I. The antioxidant and anti-apoptotic activities of selenium in the prevention of myringosclerosis in rats. J Laryngol Otol 2002; 116: 426-9. [Crossref]

28. Lii CK, Ko YJ, Chiang MT, Sung WC, Chen HW. Effect of dietary vitamin $\mathrm{E}$ on antioxidant status and antioxidant enzyme activities in Sprague-Dawley rats. Nutr Cancer 1998; 32: 95-100. [Crossref]

29. Uneri C, Bağlam T, Yazici M. The effect of Vitamin E treatment on the development of myringosclerosis after ventilation tube insertion. Int J Pediatr Otorhinolaryngol 2006; 70: 1045-8. [Crossref]

30. Islam SS, A1-Sharif I, Sultan A, A1-Mazrou A, Remmal A, Aboussekhra A. Eugenol potentiates cisplatin anti-cancer activity through inhibition of ALDH-positive breast cancer stem cells and the NF-кB signaling pathway. Mol Carcinog 2018; 57: 333-46. [Crossref]

31. Rao M, Kumar MM, Rao MA. In vitro and in vivo effects of phenolic antioxidants against cisplatin-induced nephrotoxicity. J Biochem 1999; 125: 383-90. [Crossref]

32. Binu P, Priya N, Abhilash S, Vineetha RC, Nair RH. Studies on curative efficacy of monoterpene eugenol on anti-leukemic drug arsenic trioxide induced cardiotoxicity. Biomed Pharmacother 2017; 91: 559-66. [Crossref]

33. Said MM, Rabo MM. Neuroprotective effects of eugenol against aluminium induced toxicity in the rat brain. Arh Hig Rada Toksikol 2017; 68: 27-37. [Crossref]

34. Martínez-Herrera A, Pozos-Guillén A, Ruiz-Rodríguez S, Garrocho-Rangel A, Vértiz-Hernández A, Escobar-García DM. Effect of 4-allyl-1-hydroxy-2-methoxybenzene (eugenol) on inflammatory and apoptosis processes in dental pulp fibroblasts. Mediators Inflamm 2016; 2016: 9371403. [Crossref]

35. Yadav MK, Chae SW, Im GJ, Chung JW, Song JJ. Eugenol: a phyto-compound effective against methicillin-resistant and methicillin-sensitive Staphylococcus aureus clinical strain biofilms. PLoS One 2015; 10: e0119564. [Crossref]

36. Hartnoll G, Moore D, Douek D. Near fatal ingestion of oil of cloves. Arch Dis Child 1993; 69: 392-3. [Crossref]

37. Wright SE, Baron DA, Heffner JE. Intravenous eugenol causes hemorrhagic lung edema in rats: proposed oxidant mechanisms. J Lab Clin Med 1995; 125: 257-64. [Crossref]

38. Soundran V, Namagiri T, Manonayaki S, Vanithakumari G. Hepatotoxicity of eugenol. Anc Sci Life 1994; 13: 213-7. [Crossref]

39. Goulet F, Vachon P, Hélie P. Evaluation of the toxicity of eugenol at anesthetic doses in African clawed frogs (Xenopus laevis). Toxicol Pathol 2011; 39: 471-7. [Crossref]

40. Li J, Yu Y, Yang Y, Liu X, Zhang J, Li B, et al. A 15-day oral dose toxicity study of aspirin eugenol ester in Wistar rats. Food Chem Toxicol 2012; 50: 1980-5. [Crossref] 
41. Sarrami N, Pemberton MN, Thornhill MH, Theaker ED. Adverse reactions associated with the use of eugenol in dentistry. Br Dent J 2002; 193: 257-9. [Crossref]

42. Tammannavar P, Pushpalatha C, Jain S, Sowmya SV. An unexpected positive hypersensitive reaction to eugenol. BMJ Case Rep 2013; 2013: bcr2013009464. [Crossref]
43. Rothenstein AS, Booman KA, Dorsky J, Kohrman KA, Schwoeppe EA, Sedlak RI, et al. Eugenol and clove leaf oil: a survey of consumer patch-test sensitization. Food Chem Toxicol 1983; 21: 727-33. [Crossref] 